\title{
EFEITO DA FORÇA NORMAL NO COMPORTAMENTO TRIBOLÓGICO EM ALTA TEMPERATURA DE UM AÇO RÁPIDO
}

\author{
Júlio César Giubilei Milan! \\ Sinésio Domingues Franco ${ }^{2}$ \\ Miguel Angelo de Carvalho ${ }^{3}$ \\ Renato Rufino Xavier ${ }^{4}$ \\ josé Daniel Biasoli de Mello 5
}

\section{Resumo}

No processo de laminação a quente estão envolvidas altas tensões mecânicas cíclicas, cargas essas que exercem uma grande influência sobre a vida dos cilindros. As elevadas temperaturas, inerentes ao processo, possibilitam a formação de óxidos que afetam todo comportamento tribológico do sistema. Nesse trabalho é estudado o efeito da força normal sobre o comportamento tribológico a quente de um aço rápido utilizado na confecção de cilindros de laminação de tiras a quente. Foram realizados ensaios de desgaste do tipo deslizamento alternado variando-se a força normal. Os mecanismos de desgaste atuantes foram verificados por meio de microscopia eletrônica de varredura e micro-análise química por dispersão de energia. Já o desgaste dos corpos de prova foi avaliado com o auxílio de interferometria a laser e uma rotina computacional para cálculo do volume de material removido. Os resultados mostraram um ganho de massa que aumentou com a elevação da carga. Em vez de desgaste, houve um depósito de material sobre corpo de prova na região de contato, que foi sempre crescente com a carga. Em contrapartida, o desgaste dos contra-corpos aumentou. $O$ atrito foi reduzido e o seu tempo de estabilização também apresentou a mesma tendência com a elevação da carga. Palavras-chave: aço-rápido, cilindros de laminaçăo, força normal.

\section{Effect of Normal Load on the High Temperature Tribological Behaviour of High Speed Steel}

\begin{abstract}
During the hot rolling process the surface temperature of the rolling mill rolls can reach values as high as $600^{\circ} \mathrm{C}$. In these conditions oxides may grow on the surface and change the tribological behaviour of the pair roll-strip. In this work the effect of normal load on the high temperature tribological behaviour of high-speed steel is analysed. The tribological characterization was carried out by using high temperature $\left(600^{\circ} \mathrm{C}\right)$ reciprocating sliding wear tests. The normal load was varied from 2,9 to $75 \mathrm{~N}$ whilst the other tribological parameters were maintained constant. The normal load had a strong influence on the wear rate, measured by means of laser interferometry. Wear rate was higher at room temperature. SEM analysis show that increasing the normal load facilitates the generation of oxide and assists in compaction of the debris thus producing a wear protective layer and, as a consequence, a reduction in the wear rate.
\end{abstract}

Key-words: high speed steel, hot rolling mill, normal load.

\section{INTRODUÇÃO}

Durante a larninação à quente os cilindros de trabalho estão submetidos a altas tensôes cíclicas, mecânicas e térmicas. Durante um pequeno intervalo de tempo em que os cilindros entram em contato com as tiras quentes, a temperatura de sua superfície pode atingir valores superiores a $500{ }^{\circ} \mathrm{C}$ (Stevens et al., I97I p. 3747). Essa temperatura se restringe a uma pequena espessura superficial (Stevens et al, 1971 p. 3747, Chang, 1999, p. 84), e, mesmo que momentânea devido ao resfriamento subseqüente.

A camada de óxidos gerada sobre a superfície dos cilindros exerce grande influência sobre o comportamento tribológico do sistema, e tem sido considerada como um fator de reduçâo do atrito e desgaste (Zum Gahr, 1987, p. 379; Hutchings, 1992, p. 37)

\footnotetext{
1,2,5 Faculdade de Engenharia Mecânica, Laboratório de Tribologia e Materiais, Universidade Federal de Uberlândia. Av João Naves de Ávila, 2160 , Campus Santa Mônica, Bloco IM, Uberlândia, MG, Cep 38400-902.

3,4 Aços Villares S.A., Usina Pindamonhangaba. Rodovia Luiz D. Villares, Km 2, Pindamonhangaba, SP, Cep I2400-000.
} 
O grau de redução do coeficiente de atrito depende da espessura e da composiçâo dessa camada (Luong e Heijkoop, 1981, p. 99).

Segundo Vergne et al. (200 I, p. 322), muito tem se estudado sobre o efeito das camadas de óxidos presentes nos materiais laminados, mas, pouca atenção tem sido dada à oxidação das superfícies dos cilindros e seus efeitos.

Outro fator de grande importância em relação aos óxidos é que a carnada de óxidos vai determinar a qualidade do material laminado, visto que esta carmada está presente na interface cilindrotira (Lanteri et al, 1998, p. 423).

O desgaste e o atrito vão depender das propriedades mecânicas das superfícies em contato, ou seja, dos óxidos.

A oxidação pode proporcionar, no deslizamento de duas superfícies, a transição de um período inicial de desgaste severo para um período de desgaste suave (ZUM GAHR, I987, p. 378 ; Hutchings, 1992, p. 88).

Essa transição ocorre devido ao desenvolvimento de uma camada formada a partir de partículas de desgaste oxidadas e parcialmente oxidadas, que atua como área de suporte de carga e se origina da aglomeração e compactação de partículas de desgaste finas presas a superfície de deslizamento. A altas temperaturas a compactação e sinterização permitem o desenvolvimento de superfícies vítreas compactadas, altamente deformadas e planas formadas a partir e sobre as camadas particuladas. A evolução do atrito torna-se similar à de um material sólido elástico e as taxas de desgaste se tornam muito baixas (Jiang et al., 1994, p. 186).

A carga e a velocidade exercem um papel fundamental sobre o tipo de mecanismo de desgaste atuante (So et al, 2002, p. 1012). Esses parâmetros influenciam a geração de calor na área real de contato alterando a formação (tipos de óxidos) e o crescimento de uma camada de óxidos e do mecanismo de desgaste.

Nesse trabalho é feito um estudo sobre a influência da força normal em condiçôes de alta temperatura sobre o comportamento tribológico de um aço rápido utilizado em cilindros de laminação de tiras a quente.

\section{MATERIAL E MÉTODOS}

Os ensaios foram realizados num tribômetro universal TE 67 Plint \& Partners. Durante os ensaios foram monitorados o potencial de contato e o coeficiente de atrito. A freqüência de aquisição destes dados foi de $\mathrm{I} \mathrm{Hz}$.

O material ensaiado foi um aço rápido utilizado na confecção de cilindros de laminação de tiras a quente, com dureza, $884 \mathrm{HV}_{20}$.

Como contra-corpos foram utilizadas esferas de WC-Co com $5 \mathrm{~mm}$ de diâmetro. Utilizou-se este material devido a sua elevada dureza e resistência mecânica. Com isto, pretendia-se obter um desgaste quase exclusivo dos corpos de prova e, também, uma mínima interação entre fragmentos de desgaste do contra-corpo na região de ensaio. Além disto, pretende-se elucidar os mecanismos de desgaste que não ficaram claros em trabalhos anteriores (Milan et al; 200I, p I68-177; Milan et al; 2002, p.137-146), onde não foi possível verificar a origem do material depositado sobre o corpo de prova devido à semelhança da composição química do par corpo de prova/contra-corpo.

Os corpos de prova foram extraídos de um cilindro de laminação, tendo como dimensôes finais $18 \mathrm{~mm}$ de diâmetro e $8 \mathrm{~mm}$ de espessura. As superfícies planas foram lapidadas com abrasivo $\mathrm{SiC}$, granulometria 220 , por cerca de 20 minutos para padronização das superfícies ensaiadas e, ainda, para que elas possuíssem uma topografia (rugosidade média $\mathrm{Ra}$ ) próxima da topografia inicial de um cilindro de trabalho. Imediatamente antes de ser ensaiada, cada amostra foi submetida à limpeza em ultra-som imersa em acetona, por 5 minutos.

Foram realizados ensaios de deslizamento alternado que simulam o tipo de movimento relativo dos cilindros de laminação como descrito por Milan et al. (200I, p I70). Foram utilizadas cargas de $2,9 \mathrm{~N} ; 31,4 \mathrm{~N} ; 47, \mathrm{I} \mathrm{N}$ e $75 \mathrm{~N}$ e temperatura de ensaio de $600^{\circ} \mathrm{C}$. Durante o aquecimento, o corpo de prova e o contra-corpo não estão em contato, dessa forma, quando o ensaio se inicia, o contra-corpo está à temperatura ambiente. Todos os outros parâmetros de ensaio foram mantidos constantes: amplitude de deslocamento de $6 \mathrm{~mm}$, freqüência de $6 \mathrm{~Hz}$ e tempo de ensaio de 2 horas.

Foram analisados o coeficiente de atrito, o potencial de contato e o desgaste dos corpos de prova e dos contra-corpos.

O desgaste dos corpos de prova foi medido através de dados de topografia da região do ensaio, obtidos por interferometria laser. Com o auxílio de um programa, especialmente desenvolvido para trabalhar com esses dados, foi calculado o volume de material removido na região de contato. O volume foi calculado apenas para região central $(3 \mathrm{~mm})$ da marca de desgaste, desprezando-se as bordas.

O desgaste dos contra-corpos foi obtido calculando-se o volume de material removido e a taxa de desgaste a partir do diâmetro da calota formado na esfera.

Os mecanismos de desgaste atuantes foram avaliados por microscopia eletrônica de varredura e por micro-análise química por dispersão de energia. 


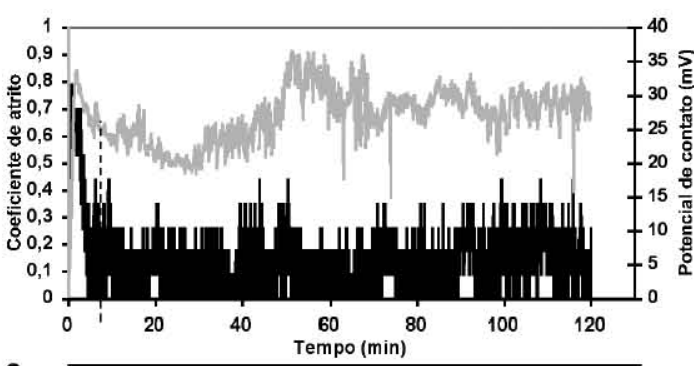

a

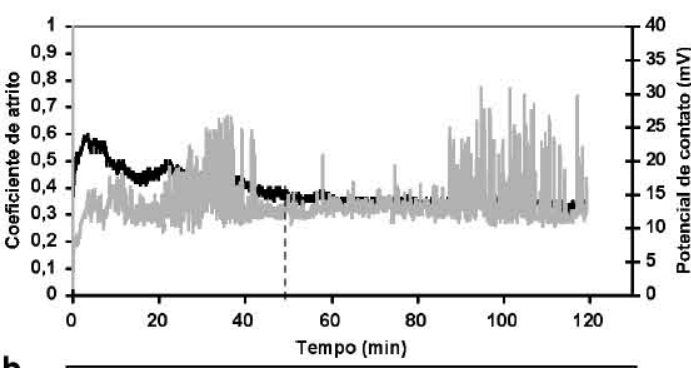

b

Figura I. Evoluçäo do coeficiente de atrito e potencial de contato obtidos em ensaios de deslizamento alternado a 600 ${ }^{\circ} \mathrm{C}$ com cargas de a) $2,9 \mathrm{~N}$ e b) $47 \mathrm{~N}$.
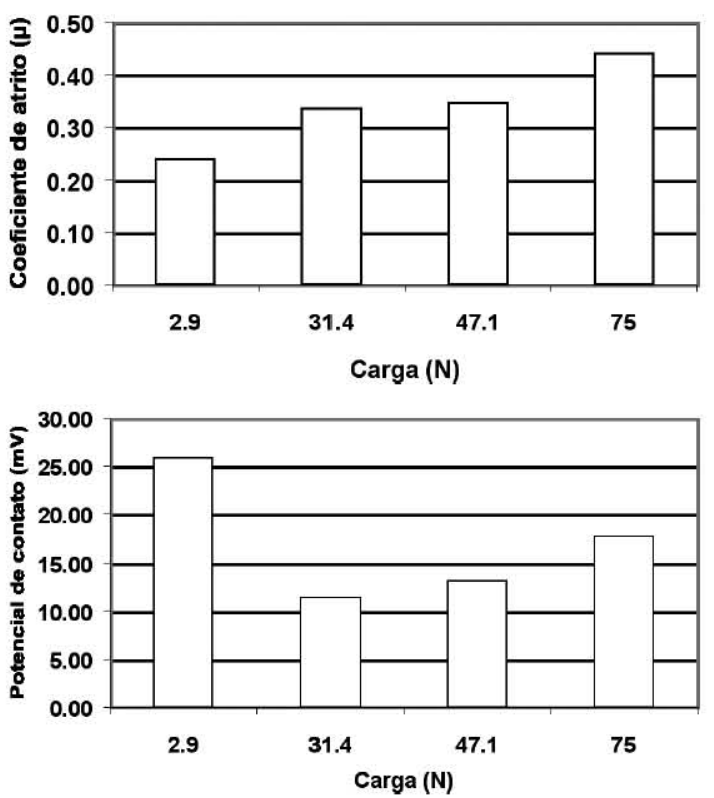

Figura 2. Resultados de (a) coeficiente de atrito e (b) potencial de contato nos ensaios de deslizamento alternado realizados a $600^{\circ} \mathrm{C}$.

\section{RESULTADOS E DISCUSSÕES}

A Figura I mostra resultados típicos da evolução do coeficiente de atrito e potencial de contato. Pode se observar nos dois gráficos que o coeficiente de atrito apresenta dois períodos distintos, separados por uma linha vertical, um pe-
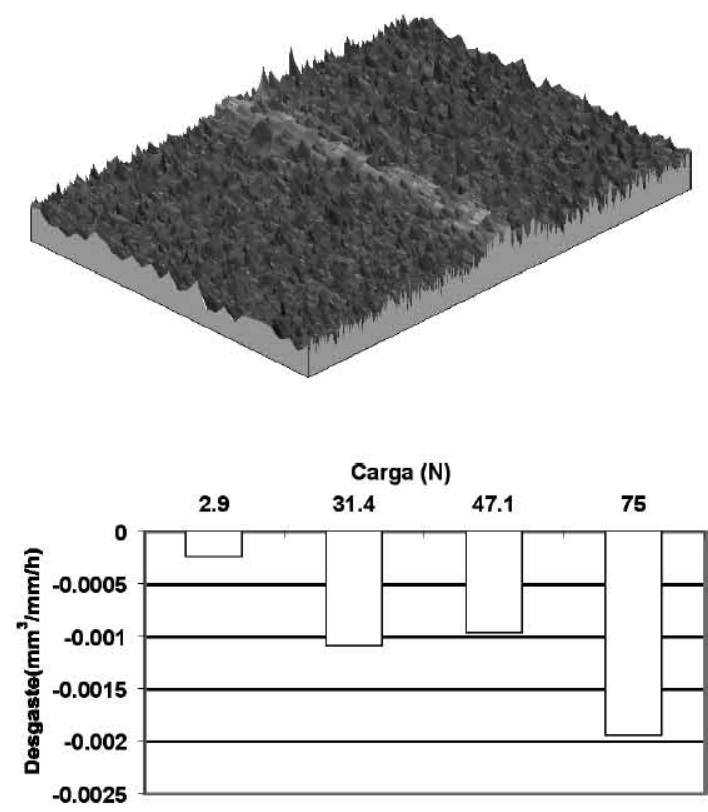

Figura 3. (a) Aspecto típico da superfície de um corpo de prova ensaiado e (b) desgaste dos corpos de prova em funçäo da carga aplicada.

ríodo inicial com valores "não-estacionários", e um segundo período que apresenta valores quase constantes. Segundo Vergne et al. (200I, p. 327) este tempo, a seguir designado de tempo de estabilização, se deve à estabilizaçâo da temperatura no contra-corpo, que inicialmente foi colocado em contato com o corpo de prova à temperatura ambiente, e, também, à geração de óxidos na interface.

A Figura 2 apresenta os valores médios de coeficiente de atrito, após a estabilização, e valores médios de potencial de contato no mesmo período. O coeficiente de atrito apresentou uma tendência de crescimento com a elevação da carga. Já o potencial de contato apresenta uma tendência de queda com elevação da carga, porém, apresentando um mínimo.

Em relação ao coeficiente de atrito, essa elevação com a elevação da carga pode ser explicada pelo aumento da área real de contato, aumentando a adesão. A queda do potencial de contato também pode ser uma explicação para o comportamento do coeficiente de atrito, porém ela serve apenas como um indicativo de que a quantidade de óxidos diminuiu. Não se pode afirmar que houve tal redução ou até mesmo que a espessura da carnada foi reduzida, pois em condições distintas podem ser gerados óxidos distintos com resistividade elétrica também distinta. Por essa razâo também se torna complicado inferir sobre os resultados de potencial de contato. $O$ aumento da área real de contato também pode ser uma explicação para a redução do potencial de contato. Com uma área real de contato maior a resistência elétrica é menor.

Desgaste - a Figura 3a, obtida por interferometria laser, mostra o aspecto típico de uma superfície de uma amostra após o ensaio. Observa-se um acúmulo (ganho) de material na região deslizada. Esse acúmulo foi crescente com a carga, ou seja, quanto maior a carga maior o depósito de material, como pode ser 
comprovado pela Figura 3b que mostra os resultados de desgaste dos corpos de prova em função da carga.

A Figura 4 mostra detalhes da superfície dos corpos de prova ensaiados com a menor e a maior carga, onde se destacam as regiōes planas de suporte de carga. Nota-se que para cargas maiores, a porcentagem dessas áreas é maior. Isso pode ser explicado pela maior deformação das asperidades com cargas maiores e devido à maior compactação dos fragmentos de desgaste proporcionado pelas altas cargas.

Essa região plana é constituída de fragmentos de desgaste proveniente do desgaste dos corpos de prova e dos contra-corpos, e, também de óxidos, como mostrado nos espectros de EDS pela presença de oxigênio. Jiang et al. (1994, p. 188) descrevem o mecanismo de formação dessas áreas planificadas. Eles indicam que essas áreas são constituídas de pequenos fragmentos de óxidos e fragmentos metálicos de desgaste que são altamente deformados
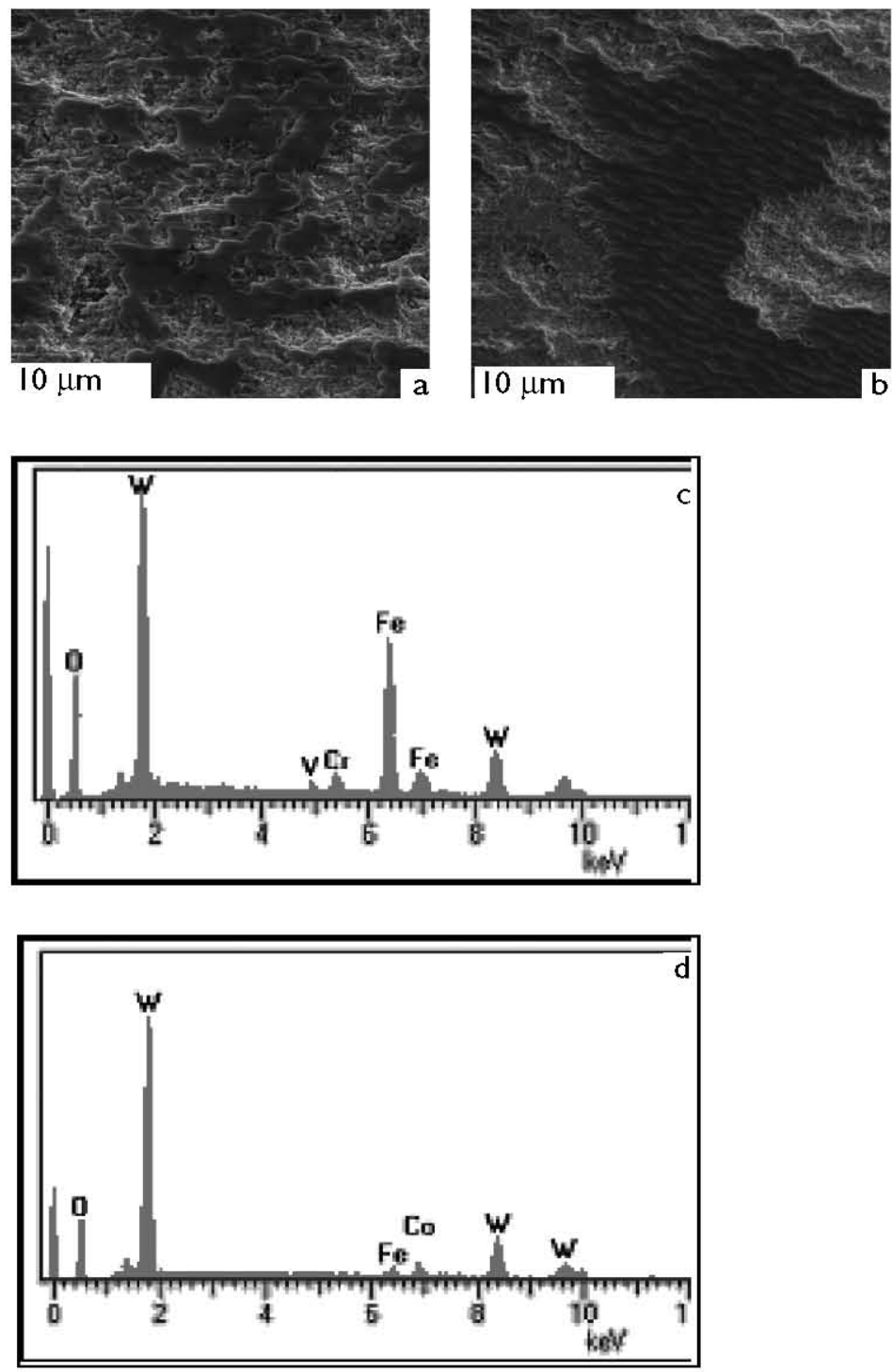

Figura 4. Micrografias da superfície dos corpos de prova, obtidas em MEV, ensaiados a: (a) $2,9 \mathrm{~N}$ e (b) $75 \mathrm{~N}$, e (c), (d) respectivos espectros de EDS das regiöes planas.
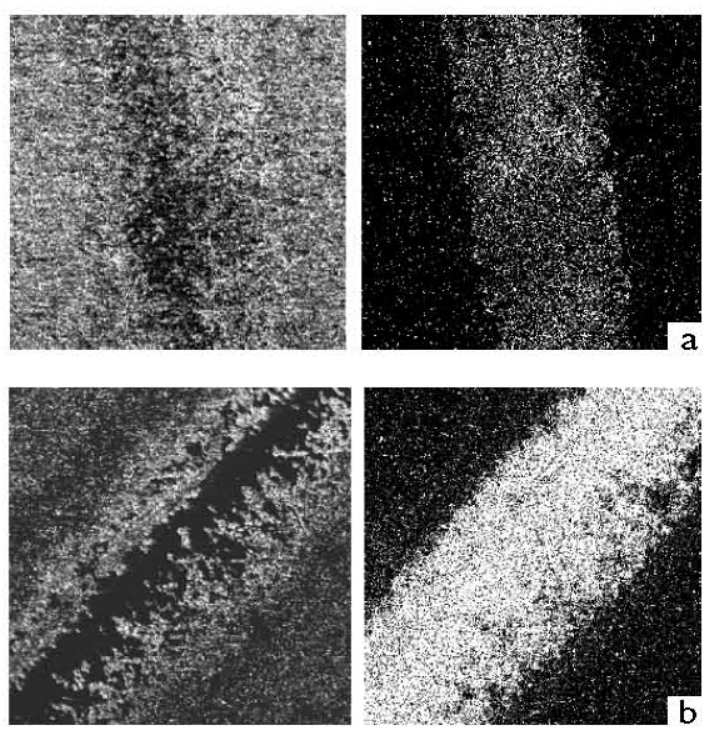

Figura 5. Aspecto superficial da região deslizada e respectivo mapa de elementos para o tungstênio nos ensaios (a) $2,9 \mathrm{~N}$ e (b) $75 \mathrm{~N}$
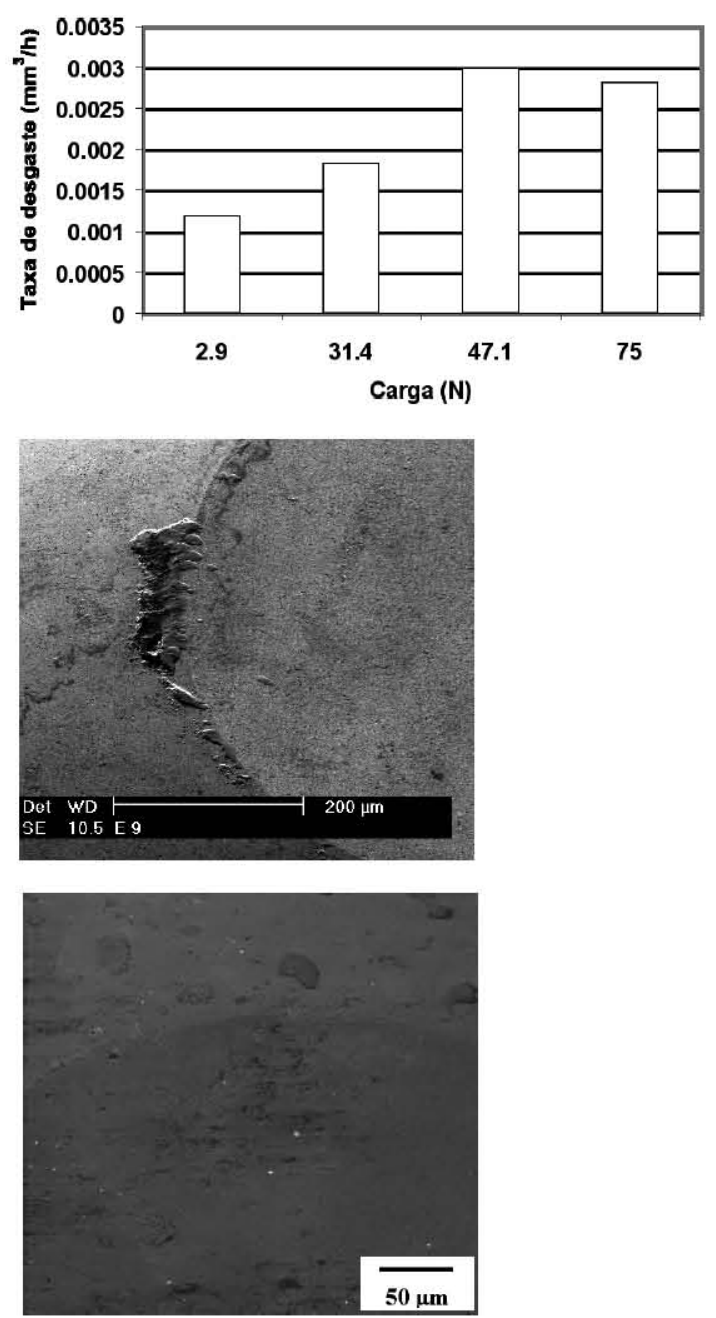

Figura 6. (a) Desgaste do contra-corpo e aspecto dos contra-corpos após os ensaios com cargas de (b) $2,9 \mathrm{Ne}$ (c) $75 \mathrm{~N}$. 
e compactados. Porém, no presente caso, verificou-se uma maior participação de fragmentos provenientes dos contra-corpos do que do próprio corpo de prova e de seus óxidos, Figura 4.

Em todos os ensaios pode ser observado que houve uma grande transferência de material entre as superfícies em contato. Isto pode ser verificado nas micro-análises químicas, Figuras $4 \mathrm{c}$ e 4 d. O tungstênio, um dos principais elementos constituintes dos contra-corpos, foi encontrado em abundância sobre a superfície do corpo de prova, como confirmado pelos mapas de distribuição deste elemento, Figura 5. Possivelmente esse elemento se encontra na forma combinada
(WC-Co). Porém, devido ao baixo número atômico do carbono, esse elemento não aparece nas micro-análises químicas, já o cobalto aparece em menor quantidade, Figura 4d.

Ocorreu um depósito de material, sobre a superfície dos corpos de prova, que foi proveniente do contra-corpo. Esse fato foi comprovado pela presença maciça de tungstênio sobre a região de ensaio. Com a elevação da carga houve um maior desgaste dos contra-corpos, Figura 6a. Conseqüentemente houve maior disponibilidade de material (WC-Co) na interface que fosse compactado, misturado com fragmentos de desgaste do corpo de prova e óxidos e, assim, formasse uma espessa camada sobre a superfície. As Figuras $6 \mathrm{~b}$ e $6 \mathrm{c}$ mostram o aspecto dos contracorpos, obtidos em MEV, nos ensaios de 2,9 e $75 \mathrm{~N}$, respectivamente.

\section{CONCLUSÕES}

A partir dos resultados obtidos nos ensaios de deslizamento alternado com variação da carga normal pôde se chegar as seguintes conclusốes:

- A carga normal exerce grande influência sobre o comportamento tribológico do aço rápido estudado, alterando o coeficiente de atrito e o desgaste;

- O coeficiente de atrito aumentou com a elevação da carga;

- O desgaste dos contra-corpos cresceu com a elevação da carga;

- A superfície dos corpos de prova apresentou um depósito de material na regiâo do ensaio em vez de apresentar crateras e

- A elevação da carga proporcionou um aumento no depósito de material sobre a superfície dos corpos de prova, em grande parte proveniente do contra-corpo.

\section{REFERÊNCIAS BIBLIOGRÁFICAS}

[I] STEVENS, P. G.; IVENS, K. P.; HARPER, P. Increasing work-roll life by improved roll-cooling practice. Journal of The Iron and Steel Institute, Tokyio, v. I, n. II, p. 3745-3755, Jan. 1971.

[2] CHANG, D. F. Thermal stresses in work rolls during the rolling of metal strip, Journal of Materials Processing Technology, Netherlands, v. 94, n. I, p. 45-5I, Sep. 1999.

[3] ZUM GAHR, K. H. Microestruture and wear of materials. Amsterdam: Elsevier, 1987. $560 \mathrm{p}$.

[4] HUTCHINGS, I. M. Tribology: friction and wear of engineering materials. London: Arnold, 1992. 273 p.

[5] LUONG, L. H. S.; HEIJKOOP, T. The influence of the scale on friction in hot metal working. Wear, Netherlands, v. 7I, n.I, p. 93-102, Sep. 198I.

[7] VERGNE, C.; BOHER, C.; LVAILLANT, L. Analysis of the friction and wear behavior of hot work tool scale: application to the hot rolling process. In: INTERNATIONAL CONFERENCE ON WEAR OF MATERIALS, I3., 200I, Vancouver. Wear, Netherlands, v. 250, n. I 12, p. 322-333, Oct. $200 \mathrm{I}$.

[8] LANTERI, V.; THOMAS, C.; BOCQUET, J.; YAMAMOTO, H.; ARAYA, S. Black oxide film generation on work rolls and its effects on hot-rolling tribological characteristics. THE INTERNATIONAL CONFERENCE ON STEEL ROLLING, 7., 1998, Chiba, Japan, 1998. Proceedings... Tokyo: The Iron and Steel Institute of Japan, 1998. p. 423428.

[9] JIANG, J;; STOTT, F. H.; STACK, M. M. Some frictional features associated with the sliding wear of the nickel-base alloy N80A at temperatures to $250^{\circ} \mathrm{C}$. Wear, Netherlands, v. 176, n.2, p. I85- 194, Aug. 1994.

[10] SO, H.; YU, D. S.; CHUANG, C. Y., Formation and wear mechanism of tribo-oxides and the regime of oxidational wear of steel, Wear, Netherlands, v.253, n. 9-10, p. 1004-10 I5, Nov. 2002. 
[I I] MILAN, J. C. G.; FRANCO, S. D.; MELLO, J. D. B.; CARVALHO, M. A.; XAVIER, R. R. Efeitos da oxidação sobre o comportamento tribológico de um aço-rápido, In: XVI CONGRESSO BRASILEIRO DE ENGENHARIA MECÂNICA, 16., Uberlândia, 200I. Anais... Uberlândia, UFU, 200I. I CD-ROM. p. I68-I77.

[12] MILAN, J. C. G.; CARVALHO, M. A.; XAVIER, R.R.; FRANCO, S. D.; MELLO, J. D. B. Efeito da temperatura sobre o comportamento tribológico de ferros fundidos multi-componentes, In: SEMINÁRIO DE LAMINAÇÃO PROCESSOS E PRODUTOS LAMINADOS E REVESTIDOS, 39., 2002, Ouro Preto. Anais... São Paulo: ABM, 2002. I CD-ROM. p. I37-I46. 